\title{
Физические свойства (упругая анизотропия и плотность) образцов горных пород массива Ярва-варака (Мончегорский район)
}

\author{
Ильченко В.Л., Нерович Л.И. \\ Геологический институт КНЦ РАН, Anamumbl, vadim@geoksc.apatity.ru
}

Аннотация. Исследованы физические свойства (плотность, упругая анизотропия) коллекции образцов горных пород с признаками шокового метаморфизма, отобранных с поверхности в районе расслоенного массива Ярва-варака (в границах предполагаемой астроблемы). Установлены заметные площадные вариации показателя упругой анизотропии и корреляция плотности пород со скоростью распространения ультразвуковых продольных волн. Выявлен ряд «аномальных» несогласий изученных физических свойств пород коллекции с аналогичными свойствами пород из других районов СВ части Балтийского щита.

Ключевые слова: массив Ярва-варака, шоковый метаморфизм, вариации физических свойств (упругая анизотропия, плотность) пород.

\section{Physical properties (elastic anisotropy and density) of rock samples of the Jarva-Varaka massif (Monchegorsk area)}

\author{
Il'chenko V.L., Nerovich L.I. \\ Geological institute KSC RAS, Apatity, vadim@geoksc.apatity.ru
}

\begin{abstract}
The physical properties (density, elastic anisotropy) of a collection of rock samples with signs of shock metamorphism sampled from the surface in the layered Jarva-Varaka massif area (within the boundaries of the supposed astrobleme) were investigated. Significant areal variations in the elastic anisotropy index and the correlation of rock density with the velocity of ultrasonic longitudinal waves were established. A number of «anomalous» unconformities were identified in the studied physical properties of studied rocks with similar properties of rocks from other areas of the NE Baltic Shield.
\end{abstract}

Key words: Jarva-Varaka massif, shock metamorphism, variations in physical properties (elastic anisotropy, density) of rocks.

\section{Введение}

Массив Ярва-варака расположен в 12 км к СЗ от г. Мончегорска и представляет собою интрузивное тело неправильной формы размером $1.7 \times 2.2$ км в плане и мощностью до 2 км, вмещающими породами являются глиноземистые гнейсы кольской серии (рис. 1). В составе интрузии участвуют породы от основного до кислого состава. Преобладают гранофировые гиперстеновые диориты, широко представлены кварцевые диориты и гранофировые нориты, чья роль увеличивается с глубиной. U-Pb возраст кварцевых диоритов составляет 2.5 млрд. лет, возраст вмещающих глиноземистых гнейсов - 2.83 млрд. лет (Смолькин и др., 2004). Все породы отличаются массивной текстурой при хорошей сохранности магматической, обычно гипидиоморфнозернистой, структуры с участками микропегматитовой и/или гранофировой.

Предыдущими исследованиями (Каулина и др., 2017) в районе массива Ярва-варака получены убедительные доказательства импактного воздействия на местные породы. Так, повсеместное присутствие значительной доли гранофира во всех породах интрузива, породные разновидности, петрохимические и геохимические особенности пород, а также значительная роль коровой контаминации указывают на то, что массив Ярва-варака наиболее близок к структуре Садбери (Нерович и др., 2015). Сегодня доминирует точка зрения, согласно которой структура Садбери возраста 1.85 млрд. лет представляет собой остатки крупного многокольцевого ударного бассейна (Grieve, 1994; Налдретт, 2003), формирование которого сопровождалось плавлением и контаминацией больших масс корового материала мишени. Массив Ярва-варака ранее был исследован на предмет петрофизики (Галичанина и др., 1976), но в этой работе всё внимание уделено плотностным и магнитным свойствам пород, а их упругие свойства не изучались. Во время полевых работ в районе 
Ярва-вараки в июле 2018 года собрана новая, петрографически довольно «пёстрая» коллекция образцов, часть которой предназначалась для изучения физических (плотность, упругость) свойств пород. Импактная природа предполагает, что породы массива Ярва-варака (и обрамления) могли сохранить следы ударного (шокового) воздействия (системы трещин), что может быть обнаружено именно в пространственных вариациях упругой анизотропии горных пород из обнажений на поверхности, чему и посвящена эта работа.

\section{Методика и результаты}

Полевыми работами в районе массива Явра-варака (2018 г.) было установлено, что выходы коренных пород, благоприятные для регулярного (прямыми профилями с равным шагом) отбора образцов встречаются здесь довольно редко. Поэтому образцы отбирались везде, где для этого были условия (рис. 1). Из обнажений отобраны пробы на разные виды анализов, в т.ч. образцы для определения физических свойств (29 точек отбора), шаг отбора - произвольный. Петрография образцов изучена в шлифах и аншлифах.
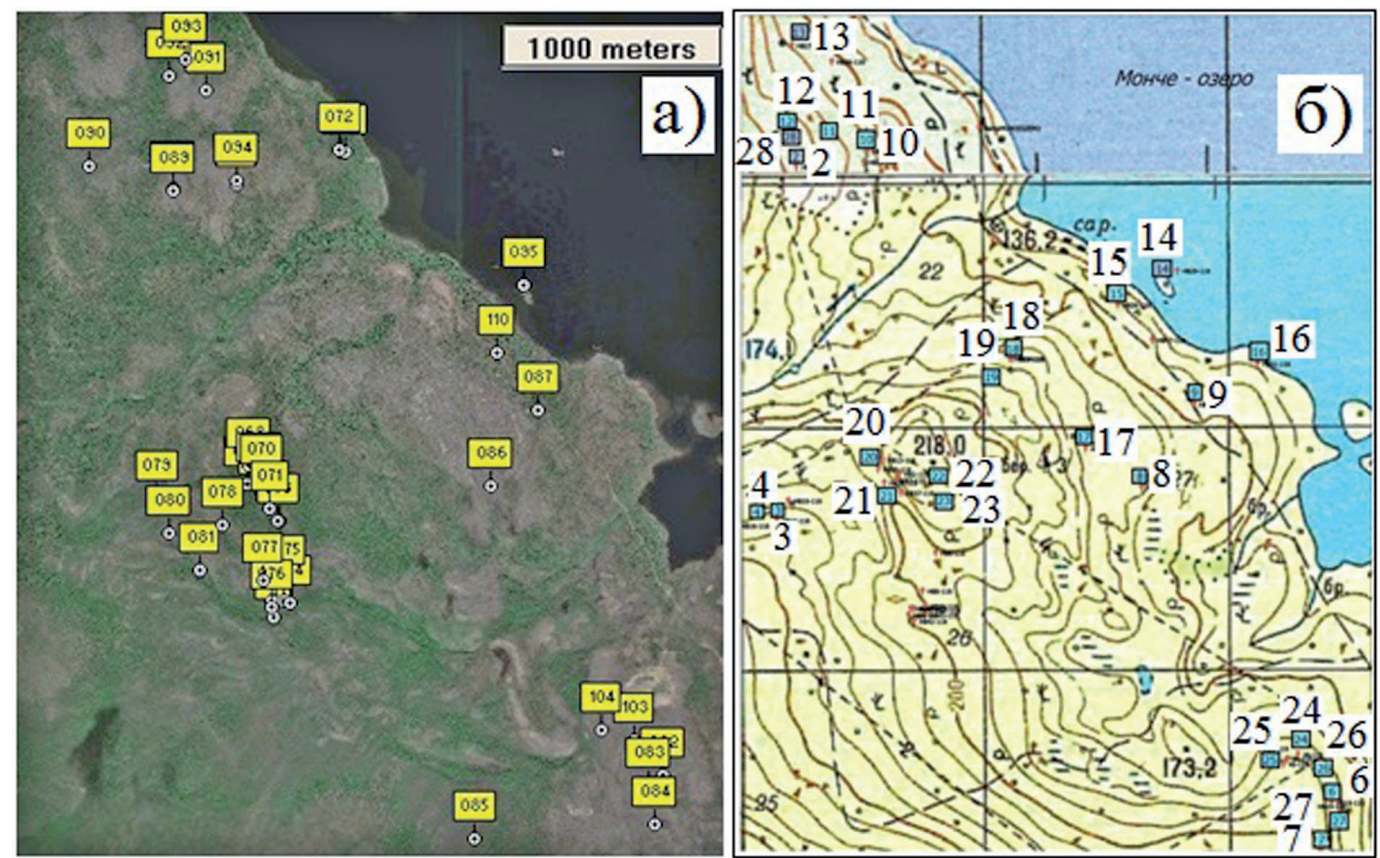

Рис. 1. Район массива Ярва-варака: слева - с нанесением JPS-точек наблюдения, справа - топографическая карта с точками отбора петрофизических проб.

Fig. 1. Jarva-Varaka massif area: a) with JPS-points of observation, б) topographic map with petrophysical sampling points.

Для проведения петрофизических измерений, из отобранных проб были выпилены образцы кубической формы (с сохранением их пространственной ориентировки), после чего их грани были пронумерованы: нормали к граням 1 и 2 - указывают, соответственно, направления на север и восток, нормаль к грани 3 - вертикаль.

Коэффициент анизотропии $A$ для образцов вычислен из скоростей распространения ультразвуковых продольных волн $\left(V_{1}, V_{2}, V_{3}\right)$, которые были измерены, соответственно, в 3-х ортогональных направлениях $(1,2,3)$, по формуле:

$$
A=1 / V_{c p} \times\left(\left(V_{1}-V_{c p}\right)^{2}+\left(V_{2}-V_{c p}\right)^{2}+\left(V_{3}-V_{c p}\right)^{2}\right)^{0.5} \times 100 \%,
$$

где $V_{c p}=\left(V_{1}+V_{2}+V_{3}\right) / 3-$ средняя скорость распространения продольных волн в образце. Скорость распространения продольных волн в образцах кубической формы измерялась на ультразвуковом приборе ГСП УК-10ПМС. Плотность ( $\rho)$ образцов определена методом Архимеда. Итоги измерений и вычислений приведены в таблице. 
Таблица. Физические свойства образцов горных пород из района Ярва-вараки.

Table. Physical properties of rock samples from the Jarva-Varaka area.

\begin{tabular}{|c|c|c|c|c|c|c|}
\hline № пா & 舟 & Горная порода & 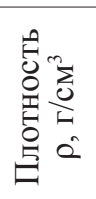 & $\begin{array}{c}\text { Скорость про- } \\
\text { дольных волн в } \\
\text { трёх направлениях } \\
\text { (км/с): } V_{1}, V_{2}, V_{3}\end{array}$ & 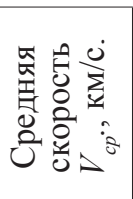 & 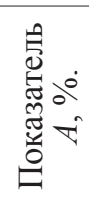 \\
\hline 1 & 2 & 3 & 4 & 5 & 7 & 8 \\
\hline 1 & $2-18$ & $\begin{array}{l}\text { Биотитовый гранит (участками гнейсовид- } \\
\text { ный), м/3 }\end{array}$ & 2.77 & $3.98,3.75,4.05$ & 3.93 & 5.65 \\
\hline 2 & $3-18$ & Диорит & 2.87 & $3.84,4.01,3.96$ & 3.94 & 3.13 \\
\hline 3 & $4-18$ & Гранодиорит & 2.76 & $4.00,3.85,3.88$ & 3.91 & 2.87 \\
\hline 4 & $5-18$ & Микроклиновый гранит & 2.65 & $3.80,3.88,3.96$ & 3.88 & 2.92 \\
\hline 5 & $6-18$ & Габбро-долерит м/з (дайка) & 3.09 & $3.55,4.07,3.82$ & 3.81 & 9.65 \\
\hline 6 & $6 a-18$ & $\begin{array}{l}\text { Биотитовый гранит (участками гнейсовид- } \\
\text { ный), м/3 }\end{array}$ & 2.77 & $4.09,3.79,3.49$ & 3.79 & 11.19 \\
\hline 7 & $66-18$ & Биотитовый аляскит пегматоидный & 2.62 & $3.65,3.65,3.40$ & 3.57 & 5.72 \\
\hline 8 & $7-18$ & Долерит с-м/3 (дайка) & 3.11 & $3.90,4.22,3.96$ & 4.03 & 5.97 \\
\hline 9 & $8-18$ & Биотитовый гнейс мигматизированный, м/3 & 2.71 & $3.66,3.76,3.63$ & 3.68 & 2.62 \\
\hline 10 & $9-18$ & Эпидот-биотитовый гнейс, м/з & 2.72 & $3.66,3.51,3.45$ & 3.54 & 4.32 \\
\hline 11 & -18 & Биотитовый гнейс мигматизированный, м/3 & 2.62 & $3.28,3.32,3.57$ & 3.39 & 6.56 \\
\hline 12 & $11-18$ & Лейкоплагиогранит пегматоидный & 2.66 & $4.02,3.65,3.53$ & 3.73 & 20.91 \\
\hline 13 & $12-18$ & $\begin{array}{l}\text { Брекчия со стекловатым цементом и } \\
\text { кластами гнейсов и гранитов (импактн }\end{array}$ & 2.87 & $3.80,3.56,3.63$ & 3.66 & 4.77 \\
\hline 14 & $13-18$ & Биотитовый гнейс, м/3 & 2.87 & $3.90,3.90,4.01$ & 3.94 & 2.28 \\
\hline 15 & -18 & Габбронорит с-кр/з & 3.27 & $2.68,2.46,2.82$ & 2.65 & 9.69 \\
\hline 16 & $15-18$ & Биотитовый гнейс, с-м/3 & 2.74 & $4.30,3.86,3.71$ & 3.96 & 10.95 \\
\hline 17 & -18 & Биотитовый гнейс мигматизированный, м/3 & 2.70 & , & 1 & 23.52 \\
\hline 18 & $17-18$ & $\begin{array}{l}\text { Биотитовый гранит (участками гнейсовид- } \\
\text { ный), м-с/3 }\end{array}$ & 2.73 & $4.02,3.88,4.15$ & 4.02 & 4.75 \\
\hline 19 & $18-18$ & Биотитовый гнейс мигматизированный, м-с/3 & 2.87 & $3.91,4.00,4.12$ & 4.01 & 3.72 \\
\hline 20 & -18 & Биотитовый гнейс, м/3 & 2.71 & $4.63,4.27,4.00$ & 4.30 & 10.39 \\
\hline 21 & $20-18$ & Биотитовый гнейс мигматизированный, м-с/3 & 2.77 & $4.24,3.76,3.70$ & 3.90 & 10.73 \\
\hline 22 & $21-18$ & Биотитовый гнейс, м/3 & 2.68 & $4.40,4.29,4.18$ & 4.29 & 3.63 \\
\hline 23 & $22-18$ & Гибридная порода & 2.93 & $3.58,3.82,3.62$ & 3.67 & 4.96 \\
\hline 24 & $23-18$ & $\begin{array}{l}\text { Биотитовый гранит (участками гнейсовид- } \\
\text { ный), с-м/3 }\end{array}$ & 2.69 & $4.18,4.44,3.78$ & 4.13 & 11.38 \\
\hline 25 & $24-18$ & Амфиболит, с/3 & 2.85 & $3.61,3.50,3.50$ & 3.54 & 2.68 \\
\hline 26 & $25-18$ & $\begin{array}{l}\text { Диорит биотит-амфиболовый (местами гней- } \\
\text { совидный), м-с/3 }\end{array}$ & 2.83 & $4.07,3.87,4.20$ & 4.05 & 5.81 \\
\hline 27 & $26-18$ & $\begin{array}{l}\text { Гранодиорит мусковит-биотитовый (места- } \\
\text { ми гнейсовидный), с/3 }\end{array}$ & 2.78 & $3.72,4.24,4.02$ & 3.93 & 9.80 \\
\hline 28 & $27-18$ & Гнейс гранат-биотитовый, м/3 & 2.66 & $3.84,4.06,3.83$ & 3.91 & 4.70 \\
\hline 29 & $28-18$ & Аналог обр. № 12-18 & 2.70 & $3.38,3.34,3.51$ & 3.41 & 3.69 \\
\hline
\end{tabular}




\section{Обсуждение результатов и выводы}

Анализ данных Таблицы на основе многолетнего опыта изучения физических свойств горных пород верхней части земной коры на СВ Балтийского щита (Ильченко, 2010 и др.) позволяет выделить ряд аномальных особенностей в породах Ярва-вараки. Например, слабоизмененные гнейсы и сланцы обычно проявляют высокие показатели упругой анизотропии $A$, тогда как мигматизированные их разности отличаются понижением этого показателя (благодаря «залечиванию» трещин по мере мигматизации). По данным Таблицы такие выводы сделать невозможно: немигматизированный и мигматизированный гнейсы № 19-18 и № 20-18 имеют близкие значения $A$ (10.39 и $10.73 \%$ соответственно). То же самое относится к прочим изменениям, происходящим в процессе частичного плавления гнейсов (сланцев), ведущих к их гранитизации и пегматитообразованию, что в обычных условиях (но не в р-не Ярва-вараки) снижает показатель упругой анизотропии. Сравним м/3 мигматизированные биотитовые гнейсы: № 8-18 $(A=2.62 \%)$ и № 16-18 $(A=23.52 \%)$ или такие же по составу гнейсы № 18-18 $(A=3.72 \%)$ и № 20-18 $(A=10.73 \%)$. Эти и другие пока ещё не вполне понятные «аномалии», на данном этапе работы, можно объяснить, по-видимому, только их «импактной» природой.

Рассмотрим графики на рисунке 2. Значения средней скорости $V_{c p}$, более чем в половине случаев находятся в прямой корреляции с величинами плотности образцов, что отвечает тенденции из справочника (Науки..., 1969) для однородных и слабоанизотропных пород.

Для сравнения по показателю упругой анизотропии разобьём нашу коллекцию на 3 части: слабая: $A \leq 5 \%$ (14 обр.), средняя: $A \approx 5-10 \%$ (8 обр.) и высокая: $A \geq 10 \%$ (7 обр.), т.е., число низкоанизотропных образцов почти равно числу средне- и высоко-анизотропных вместе взятых. Среднее арифметическое показателя анизотропии для всей этой коллекции: $A \approx 7.21 \%$. Полагая его как «границу» между повышенными и пониженными значениями, образцов с «повышенным» показателем (10) оказалось вдвое меньше, чем с «пониженным» (19). Объяснить этот факт можно так. Известно, что размер показателя упругой анизотропии обычно проявляет обратную «корреляцию» с абсолютной отметкой в точке отбора образца (Ильченко, 2010 и др.): показатель анизотропии обусловлива-

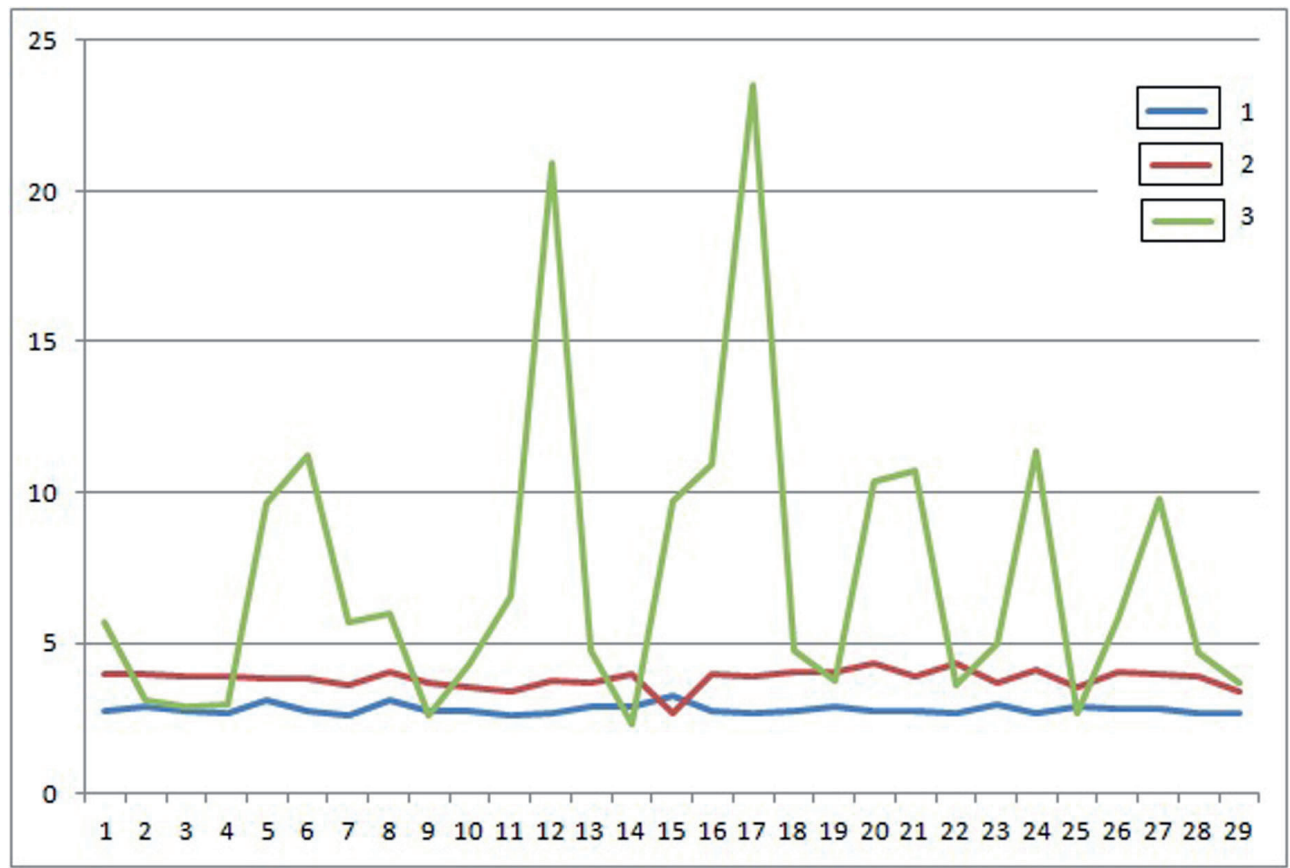

Рис. 2. Вариации физических свойств образцов изученной коллекции.

1 - плотность, 2 - средняя скорость, 3 - показатель $A$. По-горизонтали - порядковые номера образцов.

Fig. 2. Variations of the physical properties of the samples of the studied collection. 1 - density, 2 - average velocity, 3 - indicator $A$. Horizontal - serial numbers of samples. 
ет избирательность процессов выветривания; чем выше $A$, тем более анизотропна система трещин и тем легче порода разрушается. Это объяснение выглядит справедливым, если посмотреть на «карту» (рис. 1 б) с нанесенными точками наблюдения и отбора образцов: их большинство расположено на склонах именно положительных форм рельефа.

Более «убедительных» доказательств импактного влияния на упругую анизотропию и плотность пород пока найти не удалось. Но полученные результаты подтверждают смысл в новом отборе петрофизических образцов - по регулярной сетке профилей с сопоставлением новых петрофизических данных с результатами геоморфологических, геолого-структурных и петрологических исследований в районе Явра-вараки в самое ближайшее время.

Работа выполнена в рамках Госзадания ГИ КНЦ РАН, темы НИР: № 0226-2019-0052 и 02262019-0053.

\section{Литература}

1. Галичанина Л.Д., Юдин Б.А., Сараханов В.К., Гринченко Б.М., Докучаева В.С., Дубровский М.И., Латышев Л.Н., Тюремнов В.А. Петрофизическая характеристика Мончегорского рудного района. В кн.: Петрофизическая характеристика советской части Балтийского щита. Апатиты. 1976. С. 53-58.

2. Ильченко В.Л. О вариациях плотности и анизотропии упругих свойств архейских пород в приповерхностном залегании (на примере Центрально-Кольского мегаблока, Балтийский щит) // Геоэкология. Инженерная геология. Гидрогеология. Геокриология. 2010. № 1. С. 73-79.

3. Каулина Т.В., Нерович Л.И., Бочаров В.Н., Лялина Л.М., Ильченко В.Л., Кунаккузин Е.Л., Касаткин И.А. Рамановская спектроскопия импактного циркона из расслоенного массива Ярва-варака (Мончегорский рудный район, Кольский полуостров) // Вестник МГТУ. 2017. Т. 20. № 1/1. С. DOI:10.21443/1560-92782017-20-1/1-72-82. С. 72-82.

4. Налдретт А. Дж. Магматические сульфидные месторождения медно-никелевых и платинометальных руд. СПб. Изд-во СПбГУ. 2003. 487 с.

5. Науки о Земле. Т. 21. Пер. с англ. Справочник физических констант горных пород. Под ред. Г.Д. Афанасьева, Б.П. Беликова, М.П. Воларовича. М. Изд-во: МИР. 1969. 544 с.

6. Нерович Л.И., Баянова Т.Б., Кунаккузин Е.Л., Базай А.В., Некипелов Д.А. Новые результаты геологопетрографического и геохимического изучения расслоенного массива Ярва-варака, Мончегорский рудный район // Труды Ферсмановской научной сесии ГИ КНЦ РАН. 2015. Т. 12. С. 141-146.

7. Смолькин В.Ф., Федотов Ж.А., Нерадовский Ю.Н., Баянова Т.Б., Борисова В.В., Глазнев В.Н. Расслоенные интрузии Мончегорского рудного района: петрология, оруденение, изотопия, глубинное строение. Ч. 1. Апатиты. Изд-во: КНЦ РАН. 2004. 177 с.

8. Grieve R. A. F. An impact model for the Sudbury structure // Proceedings of the Sudbury-Noril'sk Symposium: Ontario Geological Survey Special Volume. 1994. V. 5. P. 119-132. 